\title{
Vulnerability to Sea Level Rise: A Novel Local-Scale Indicator-based Assessment Methodology and Application to Eight Beaches in Shoalhaven, Australia
}

\author{
Fahim Nawroz Tonmoy (Corresponding author) ${ }^{1,2}$
}

1. Coastal Zone Specialist, National Climate Change Adaptation Research Facility (NCCARF), G39 Griffith University, Gold Coast, QLD4222, Australia. Email f.tonmoy@griffith.edu.au, Phone +61755528290

2. Adjunct Lecturer, School of Civil Engineering, University of Sydney, Email: fahim.tonmoy@sydney.edu.au

Abbas El-Zein Professor of Environmental Engineering, School of Civil Engineering, J05 University of Sydney, NSW 2006 Australia Email: abbas.elzein@sydney.edu.au

\begin{abstract}
Vulnerability of a socio-ecological system to one or more climatic hazards depends on climatic, geophysical, socio-economic and institutional factors. In addition, vulnerability is a scale- and place-dependent concept. While decision-making on adaptation is often made by local government, only a small number of local-scale assessments have been conducted. When indicators are used, global utility functions based on additive or multiplicative aggregation implicitly assume complete compensation between indicators, implying that one source of vulnerability (e.g., proximity to the sea) can always be compensated for by an advantage in another source (e.g., strong social or economic capital) when evidence shows that this is not always the case.

This paper presents an indicator-based assessment of vulnerability of eight beaches in Shoalhaven, New South Wales, that are especially exposed to sea level rise. Its goal is twofold. First, it illustrates how indicator-based vulnerability assessments can be applied at a local scale - and not just sectoral, regional and national scales with the aim of informing local government adaptation planning and resource allocation. In the process, models operationalising the concepts of exposure, sensitivity and adaptive capacity are developed for two valued attributes identified through discussions with the council, namely the well-being of beach residents and the wellbeing of users of infrastructure systems located at the beaches. The usefulness of this local-scale assessment is further discussed.
\end{abstract}

Second, the paper studies, for the first time, the way outranking procedures can be applied in real-life vulnerability assessments as a form of data aggregation that better reflects the non-compensatory nature of many vulnerability indicators. The strengths and weaknesses of the outranking approach are discussed, especially the extent to which the concepts of preference, indifference and dominance thresholds can be conveyed to, and their values elicited from, stakeholders.

Keywords: Climate change vulnerability; adaptation; multi-criteria analysis; sea-level rise; coastal zone management; decision making; outranking

\section{INTRODUCTION}

Sea level rise may accelerate the erosion of coastal margins, threatening surrounding land, property and infrastructure systems. Forty-five out of 63 most populated cities of the world - namely those with 5 million or 
more inhabitants in 2011 - are located on or near the coast (United Nations, 2012). The vulnerability of coastal settlements, communities and infrastructure systems to sea level rise has received increasing attention in the literature over the last decade (Walsh et al., 2004; McInnes et al., 2016).

Vulnerability assessments, both quantitative and qualitative, can be useful analytical exercises informing and rationalising decisions on adaptation (Birkmann, 2007, Kienberger et al., 2013). The concept of vulnerability takes into account both geo-physical and socio-economic components of risk (Kelly and Adger, 2000, O'BRIEN et al., 2007). In other words, it is not just the extent of exposure of a socio-ecological system (SES) to the hazard in question that matters but the ramifications of that exposure, including the SES's ability to cope with and adapt to it $^{1}$. Assessments of vulnerability found in the literature suffer from a number of limitations, two of which are of particular concern to us here.

First, where indicators are used, utilitarian aggregation approaches - such as additive or multiplicative aggregations - do not take into account the non-compensatory nature of different processes generating vulnerability (e.g., beyond a certain threshold of sea level rise, no level of adaptive capacity of small Island states can help overcome the impacts of the hazard, i.e., an increase in adaptive capacity may not compensate for an excess in exposure to the hazard). Most indicator-based assessments use additive aggregation with equal weights without providing justification for the utility function as a proxy for vulnerability and without discussing how a different choice of weights might affect analytical outcomes (Tonmoy et al., 2014). Additive aggregation is ideally suited to contexts in which all indicators are convertible to a single (usually monetary) value. However, many scenarios exist where this single-value approach may not be well suited.

Outranking procedures, developed in decision science precisely to deal with the non-compensatory nature of decision criteria, use pairwise comparisons of SESs to rank their vulnerabilities, without the need for any global utility function. They have recently been suggested as better aggregation alternatives for ranking vulnerabilities and better identify the structure of stakeholder preferences and norms (Cinelli et al., 2014, El-Zein and Tonmoy, 2015, El-Zein and Tonmoy, 2017). However, these procedures typically require additional data to be elicited from stakeholders in order to characterise the extent and limits of compensation. There is no literature on this topic in the vulnerability literature and very little in the decision-science outranking literature (e.g., Figueira et al., 2002; Kodikara et al., 2010). To date, no attempt appears to have been made at applying outranking procedures to a reallife assessment case study; hence, their ability to offer a viable aggregation alternative has not been tested.

Second, vulnerability is a scale-dependent concept, i.e. it is likely to be conceived of, operationalised and assessed, differently at different spatial and temporal scales (e.g, Sterr et al., 2003, McLaughlin and Cooper, 2010, Tavares et al., 2015). In addition, it is place-dependent which means that processes generating vulnerability are determined by place-specific factors, in addition to regional, national and global ones (Dolan and Walker, 2006; Douglas et al., 2012). The scale at which assessments are actually conducted is usually determined by the policy questions and institutional structures and processes that have brought them about, rather than the scale at which key processes occur. Hence, mismatches between process scale, observation scale, analysis scale and policy scale are common in coastal problems (Wu et al., 2006; Kienberger et al., 2012). Regional and national authorities typically

\footnotetext{
${ }^{1}$ We follow Norgaard (2006) in defining a Socio-Ecological System (SES) as SES as a coupled humanenvironment system which includes a 'bio-geo-physical' unit and its associated social actors and institutions.
} 
have more capacity to conduct assessments, compared to local authorities. However, coastal planning is often developed and implemented by local authorities for whom larger-scale studies are necessary but may not be sufficient. Indeed, choices faced by local authorities require a different kind of vulnerability assessment that is finer in scale, tailored to help answering specific policy questions and informed by place-specific data and values. Unfortunately, there is a dearth of such assessments in the literature, compared to those conducted at the level of regions, nations or economic sectors (Tonmoy et al., 2014). Concepts such as exposure, sensitivity, susceptibility, resilience and adaptive or coping capacities are typically used as a way of operationalising vulnerability as a concept; however, very few attempts appear to have been made at developing working definitions for these concepts at a local scale.

This paper builds on our previous works ((El-Zein and Tonmoy, 2017, El-Zein and Tonmoy, 2015)) and presents an application of indicator-based assessment of vulnerability to sea level rise of eight beach communities in Shoalhaven, New South Wales (NSW) conducted between January and December 2013. Its goal is twofold. First, it illustrates how indicator-based vulnerability assessments can be applied at a local scale - and not just sectoral, regional and national scales - to inform local government adaptation planning and resource allocation. In the process, a model operationalising the concepts of exposure, sensitivity and adaptive capacity is developed for two valued attributes, namely the well-being of beach residents and the functionality of the infrastructure systems located at the beaches. Challenges, opportunities and limitations presented by local vulnerability assessments are hence analysed and discussed. Second, the paper studies the way outranking procedures can be applied in vulnerability assessments as a form of data aggregation that better reflects the typically non-compensatory nature of sets of vulnerability indicators. The strengths and weaknesses of the outranking approach are discussed, especially the extent to which the concepts of preference, indifference and dominance thresholds can be conveyed to, and their values elicited from, stakeholders.

The remainder of the paper is divided into four parts. First, we present the study area and policy needs for which the vulnerability assessment has been conducted. Second, the vulnerability models are developed and the outranking procedure used for ranking the vulnerabilities of the eight beach communities described. Third, the consultation process is discussed. Finally, results are presented and discussed, implications for vulnerability assessments elicited and future research directions suggested.

\section{STUDY AREA AND HAZARDS IDENTIFICATION}

Shoalhaven City (SC) is located on the south coast of New South Wales, about 163 kilometres south of Sydney (Figure 1). SC encompasses a total land area of about 4,561 square kilometres, including substantial areas of national park, state forest, bushland, beaches and lakes. Most of the population is concentrated along the coastal fringe, in major centres and numerous small settlements. In addition to its permanent residents, this area has attracted a significant amount of tourists over the years, and is currently the most visited local government area (LGA) in NSW outside of Sydney. The population grew from about 29,000 in 1971 to nearly 100,000 in 2017 with a forecast of 20\% growth by 2036 (Shoalhaven City Council, 2017). The Shoalhaven City Council (SCC) manages residential and commercial developments and develops and maintains a number of public infrastructures around the coast to provide basic services to its residents. It is responsible for long-term planning for adaptation to climate change in the Shoalhaven area. "Shoalhaven Water", part of the SCC, is responsible for 
managing water and waste water infrastructure worth over 1 billion AUD that include 218 sewerage pumping stations, 1,229 kilometre of waste water pipes, 1,621 kilometres of water pipe lines and 1,500 water mains among other (Shoalhaven Water, 2012). In terms of transportation, the SCC maintains 1637 kilometre of roads which are crucial for Shoalhaven’s residential, business and economic lives (Strategic Planning \& Infrastructure Group, 2012) .

Significant flooding and beach erosion events along the Shoalhaven coastline occurred in 1974, 1978, 1986 and 1998 and are associated with storms triggered by an intense low pressure system called the East Coast Low (Hough et al., 2010). The most recent East Coast Low event in June 2016 caused significant erosion damage in Currarong beach (Royal Haskoning DHV, 2016) . Most climate model projections conducted specifically for NSW coasts, predict an annual increase in the frequency of such low pressure systems (Refsgaard et al., 2007, Shand et al., 2011a). Sea level rise (SLR) may compound the problem by providing a higher base which increases the height of storm surges and/or acting as a higher seaward barrier restricting the escape of flood waters caused by excessive runoff (Walsh et al., 2004, Shand et al., 2011b). In addition, SLR may accelerate the erosion of coastal margins, threatening surrounding land, property and infrastructures. The following three hazards have been identified as most relevant for Shoalhaven beaches (Adamantidis et al., 2009):

- short-term coastal erosion including that resulting from severe storms, the behaviour of estuary entrances and slope instability;

- long-term coastline recession including that resulting from imbalances in sediment budget, such as Aeolian sand transport, sea level rise and beach rotation;

- $\quad$ oceanic inundation of low-lying areas.

In a study commissioned by the SCC, Nielsen and Varley (2004) have identified eight beaches that are most at risk from long-term erosion and inundation. These are Callala Beach, Shoalhaven Heads, Culburra Beach, Currarong Beach, Collers Beach, Mollymook Beach, Warrain beach and Collingwood Beach (see Figure 1). Key demographic and socio-economic data about the eight beaches are given in Table 3. The SCC has commissioned further individual hazard studies for each of the eight beaches (see (Adamantidis et al., 2009)). for details). Outputs of these studies are hazard lines for each beach under two scenarios of sea level rise (2050 and 2100) which can be used to identify assets and households exposed to sea level rise. These hazard lines are taken as a starting point for the vulnerability assessment conducted in this paper.

\section{DEVELOPMENT OF INDICATOR-BASED VULNERABILITY MODELS AND AGGREGATION FRAMEWORK}

\subsection{Basic Definitions}

Following Hinkel (2011), we understand vulnerability as susceptibility to harm of one or more valued attributes (e.g., economic prosperity, physical assets, well-being, health and safety) of a socio-ecological system (e.g., neighbourhood, community, industrial sector) to one or more hazards (e.g., sea level rise, heat waves, 
earthquakes) within a given time horizon (e.g., present time, 2050, 2100). Hence, vulnerability, according to this definition, is a pre-existing condition of the SES and depends on both indigenous characteristics of the SES and exogenous factors related to the hazard.

In order to assist the SCC in prioritising short- and long-term planning for adaptation at the eight beaches in question, our goal is to rank the vulnerabilities of the communities living at, or in the vicinity, of these beaches and develop a better understanding of the most important drivers of vulnerability, taking into account both geophysical and socio-economic elements of risk. After deliberations with the SCC, it was decided to limit consultation to SCC experts and managers, for two reasons. First, it was important from the SCC's point of view that, prior to any wider community consultation, necessary analytical assessment be conducted internally by way of preparation. Second, testing some of the research ideas proposed in this paper (outranking, thresholds of difference) was better conducted in the first instance, with a smaller set of stakeholders.

As a first step towards building models of vulnerability, it is necessary to specify the terms shown above in italics for the problem at hand. After consultation with the SCC and in light of the specific policy aims of the SCC, we identified two valued attributes of concern:

a. The well-being of users of services provided by infrastructure components located at the beaches in question (whether the users live near the beach or not).

b. The well-being of residents at or near the eight beaches in question;

In other words, the SESs associated with the two valued attributes defined above are different, with the first being potentially much larger than the second. This is because impact of damage to infrastructure systems goes beyond beach residents and may affect Shoalhaven residents that live far from the beach. In addition, while some overlap exists, processes determining vulnerability in the two cases are distinct and, in our discussions with the SCC, it became clear that it wished to consider both valued attributes in its planning. Hence, two models are developed, corresponding to points $\mathrm{a}$ and $\mathrm{b}$ above. Key definitions related to the two models are given in Table 1. We use the prefix SEVA (Sydney Environmental Vulnerability Assessment) and call these two models SEVA-HOUSE and SEVA-INFRA, respectively. Clearly, it would be desirable to be more specific about what is meant by "well-being" in the definitions of the valued attributes, by eliciting important values from communities concerned and a "lived-value typology" as argued for example by Graham et al. (2014). However, this would require more extensive qualitative research amongst the communities concerned and was beyond the scope of the current research project.

The choice of timeframe for the study has emerged from two considerations. The hazard studies described earlier are the most detailed geophysical description of the hazards available to us, and have dictated the choice of the 1974 storm as a reference, albeit under a 2050 scenario of $0.4 \mathrm{~m}$ projected sea level rise, as recommended by the New South Wales government at the time of the study (NSW, 2009). On the other hand, setting our time horizon at 2050, as consistency demands, would have required unrealistic projections of socio-economic indicators more than 35 years into the future. Hence, a simpler approach is to ask how the SESs under study would be affected should the storm event, as defined above, occur today. Another advantage of this definition is its ease of communication to stakeholders. 
In consultation with the SCC, three infrastructure systems are identified as important in determining the SCC's ability to maintain public services: water supply, waste water transportation and roads. In addition, Shoalhaven earns significant revenues from its tourism activities and therefore public amenities such as a golf course in Mollymook and surf clubs in Mollymook, Warrain and Shoalhaven Heads are included in the model. The electrical grid and telecommunication systems are left out of the analysis because of the unavailability of suitable data.

\subsection{Development of vulnerability models and selection of vulnerability indicators}

Vulnerability indicators are selected through which SEVA-HOUSE and SEVA-INFRA can be made operational, i.e. used as a basis for ranking vulnerabilities. This is done in two stages. First, definitions of the three dimensions of vulnerability are written for each of the two models, in order to produce an understanding of these concepts that is mutually agreed between researchers and SCC stakeholders. These are given in Table 2. The definitions of sensitivity and adaptive capacity for SEVA-INFRA deserve some clarification. "Sensitivity" is viewed as comprising two elements a) the impact of the disruption of public infrastructures on households and b) the capacity of authorities to replace or restore the service. A more intuitive approach would have included point b in the definition of “Adaptive Capacity”, rather than "Sensitivity”. This is exactly what we did initially. However, through discussions with SCC stakeholders, it became clear that, in eliciting a quantitative measure of expected impacts on users, it was difficult to separate it from the SCC's ability to replace/repair the service. This is because the extent of disruption to households depends on how long the SCC need to restore the service under stress. Hence, in the model, impacts and speed of restoration, are lumped together. Adaptive Capacity, on the other is defined as the ability of users to do without the service, i.e. it measures how critical the service is, which is clearly distinct from the ability to repair by the SCC.

Second, a set of indicators is selected for each one of these dimensions, in consistency with the definitions shown in Table 2 and in collaboration with the SCC. Vulnerability indicators have to satisfy the following requirements: a) to reflect, as much as possible, the most significant processes driving a particular dimension of vulnerability, and b) to be readily available or measurable with reasonable confidence. A comprehensive list of all indicators, for both models, is given in the supplementary material. We present and discuss these indicators next.

\subsubsection{Indicators for SEVA-INFRA}

Exposure of infrastructure systems to SLRAP is represented by the replacement cost of damaged infrastructure as a result of the hazard (as defined earlier). These are estimated from the output of the hazard studies discussed earlier. Infrastructure systems of Shoalhaven that are likely to be affected by SLRAP are divided into four categories: sewerage, water supply, roads, and relevant public amenities (e.g., golf course, surf club, car park, etc.) and each allocated a set of indicators, reflecting different key components of the system (3 indicators for sewerage, 2 for water supply and 1 each for roads and public amenities).

Different sensitivity indicators are used for each of the different infrastructure systems. Indicators for sewerage

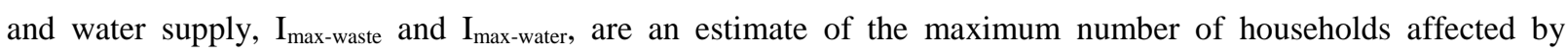
disruption of service as a result of the storm. They are generated from an infrastructure interdependency system dynamics (SD) model developed by the authors specifically for the purpose. The model takes into account 
cascading failures and dependencies of different components of the two systems (water and sewerage) on each other. (For more details on the system dynamics models, see Tonmoy and El-Zein, 2013, Hasan et al., 2015). Building an infrastructure interdependency model allows us to estimate the impact of an infrastructure disruption that goes beyond the boundary of the beach community since at-risk infrastructure provide supply to other parts of Shoalhaven, not just one beach community. SD models have been developed only for Mollymook and Collingwood as these are the only two beaches that had at-risk infrastructure with dependencies. For the other beaches, count of households affected by the disruption of a given infrastructure service is more straightforward.

The sensitivity of roads to a storm event is quantified through two impact categories (e.g., direct and indirect impacts). Disruption of traffic during the reference event leading to loss of direct access to any private properties is regarded as direct impact (R1). On the other hand, indirect impacts R2, measures disruption based on traffic volume and service category (e.g., arterial, collector or local road). The sensitivity of public amenities is represented by $\mathrm{R} 3$, which is a relative measure of the estimated number of affected individuals if the amenity in question is damaged. Details of these variables (R1, R2, and R3) are given in Table A2 of the supplementary material.

Finally, the adaptive capacity of users is captured by expert and stakeholder judgement about the degree to which the disrupted service is critical, i.e. the extent to which it serves a vital function (e.g., the water supply is more vital than a car park at a beach). In other words, adaptive capacity in this case is reflected by the extent to which users can do without the service in question. The indicators are shown in Table A5 of the supplementary document.

\subsubsection{Indicators for SEVA-HOUSE}

The exposure of a household living at or near the beach to SLRAP is assumed to occur through the exposure of its property (be it owned or rented). Sensitivity is measured by the number of people affected by property damage and disruption to infrastructure services, but unlike the sensitivity of SEVA-INFRA, only including those living at or near the beach. Finally, the adaptive capacity is captured through a set of socio-economic indicators for the whole beach. Existing literature identifies cultural beliefs, norms, and lack of access to resources and political power as important determinants of the capacity to adapt to a certain risk. Key papers in this field (Blaikie P, 1994, Cutter, 1996, Hewitt, 1997, Cutter et al., 2000, Clark et al., 1998, Tobin and Montz, 1997) have demonstrated that demographic and housing characteristics such as age, gender, race, income, education, and living conditions are important in amplifying or reducing the overall vulnerability to hazards (Wu et al., 2002). Following the concepts illustrated in Wu et al. (2002) a list of adaptive capacity criteria was presented to the SCC and only ten of those deemed relevant to the context of Shoalhaven - were retained (Table A12 of supplementary material).

\subsection{Outranking framework for aggregation of vulnerability indicators}

\subsubsection{Background}

The goal of the assessment exercise is to assist the SCC in prioritizing action by ranking the vulnerabilities of the eight beaches, taking into account both geophysical and socio-economic elements of risk. Hence, it is necessary to aggregate the indicators selected earlier in order to generate such a ranking. Aggregation of indicators for the purpose of building indices or ranking alternatives has received significant attention in the literature and a review of the different approaches with their pros and cons is beyond the scope of this paper (e.g., Ebert and Welsch, 
2004, Böhringer and Jochem, 2007, Füssel, 2007, Klein, 2009, Tonmoy et al., 2014). The most common aggregation approach used in the literature generates a global arithmetic utility function (additive or multiplicative, either weighted or not). While easy to implement and communicate, the approach suffers from a number of drawbacks, three of which are especially important here (Tonmoy et al., 2014). First, arithmetic aggregation requires the conversion of all indicators to a common scale when in fact, in many cases, there is little objective basis for such conversions. This is known as the problem of incommensurability. Second, sets of indicators are often heterogeneous, i.e. they are made of different types of data reflecting different levels of uncertainty and subjectivity in the process of indicator selection and quantification. The contrast between different indicators in our own framework, described earlier, illustrate this point well. For example, while the replacement cost of infrastructure asset at risk is expressed in monetary value on a continuous scale (indicators I20 and I21), the service value of the asset is expressed on an ordinal (i.e. semi-qualitative) scale, through stakeholders' judgment (indicators I22 to I24). The uncertainty attached to the former is of a different nature and magnitude to the one associated with the latter, a common feature of sets of indicators that is difficult to take into account by arithmetic aggregation. Third, for a rigorous application of arithmetic aggregation, linear independence of indicators is required, without which the aggregation loses some validity. This condition is very difficult to achieve when working with sets of indicators.

In this paper we follow a different approach to aggregation. Outranking procedures are a collection of different methods, developed in multi-criteria decision analysis (MCDA) that generate rankings of comparable objects through structured pair-wise comparisons without having to build a global utility function. As a result, outranking based approaches have two significant advantages over arithmetic aggregation that are highly relevant in the context of indicator based vulnerability studies (IBVA):

a) their theoretical requirements are less stringent than utilitarian approaches, allowing for a higher level of uncertainty (e.g., no requirement for linear independence of indicators or complete knowledge of stakeholders’ preferences) and

b) they are based on a fuzzy preference structure which allows for partial or no compensation between indicators.

First proposed by Roy (1968), outranking procedures have since been applied to infrastructure and environmental decision making studies to help policy makers choose between different alternative actions under conflicting criteria and high levels of uncertainty (Hokkanen and Salminen, 1997, Kangas. A, 2001, Figueira et al., 2005, Brooks, 2003, El Hanandeh and El-Zein, 2010).

In earlier work, we developed and tested an outranking framework for aggregation in indicator-based vulnerability assessments (IBVA), called the Sydney Environmental Vulnerability Assessment (SEVA) framework (El-Zein and Tonmoy, 2015). This was based on the ELECTRE III outranking procedure (Roy, 1978). Among other outranking models, we chose to use ELECTRE-III because of its non-compensatory preference structure, which will be outlined in the next section. However, the framework has not yet been applied to a real-life case of assessment, involving the eliciting of preferences from stakeholders. Hence, how well the aggregation approach and its data requirements work in practice is an important research question that this paper aims to address. Next we provide a 
summary of the framework. For a more extensive description, the reader is referred to El-Zein and Tonmoy (2015).

\subsubsection{SEVA Outranking Framework}

We start with a set of $n$ vulnerability indicators for a set m SESs, $I_{i j}(i=1, n ; j=1, m)$, which we refer to as a vulnerability matrix (mxn). We assume, without loss of generality, that the higher the value $\mathrm{I}_{\mathrm{i}}$, the more vulnerable the SES. Conceptually, vulnerability $V_{j}$ of SES $j$ can be seen as an unknown function of $I_{i j}$, i.e., $V_{j}=f\left(I_{1 j}, I_{2 j}\right.$, $\left.\mathrm{I}_{3 \mathrm{j}}, \ldots, \mathrm{I}_{\mathrm{nj}}\right)$. Function $\mathrm{f}$ cannot be known or built based on deductive arguments. Hence, an alternative way of ranking vulnerabilities is pursued, one which doesn't require the explicit evaluation of function $f$, and is based on fuzzy descriptions of the relationships between vulnerability and individual indicators.

For each pair of SESs, a and b, three different categories of relative vulnerability can be defined:

i) $\quad b$ is strictly more vulnerable than a according to the $i_{\text {th }}$ indicator, $I_{i}$, if and only if $I_{i b}-I_{\text {ia }} \geq p_{i}$, where $\mathrm{p}_{\mathrm{i}} \geq 0$ is the relative vulnerability threshold for indicator $I_{i}$;

ii) $b$ is indifferent to a according the $i_{t h}$ indicator, $I_{i}$, if and only if $\left|I_{i b}-I_{i a}\right| \leq q_{i}$, where $q_{i} \geq 0$ is the indifference threshold for indicator $I_{i}$;

iii) $b$ is weakly more vulnerable than a according to the $\mathrm{i}_{\text {th }}$ indicator, $\mathrm{I}_{\mathrm{i}}$, if and only if $\mathrm{q}_{\mathrm{i}}<\mathrm{I}_{\mathrm{ib}}-\mathrm{I}_{\mathrm{ia}}<\mathrm{p}_{\mathrm{i}}$;

iv) $b$ is strictly more vulnerable than a according to the $\mathrm{i}_{\text {th }}$ indicator, $\mathrm{I}_{\mathrm{i}}$, and regardless of its performance on other indicators, if and only if, $\mathrm{I}_{\mathrm{ib}}-\mathrm{I}_{\mathrm{ia}}>\mathrm{v}_{\mathrm{i}}$, where $\mathrm{v}_{\mathrm{i}}>\mathrm{p}_{\mathrm{i}}$ is the dominance threshold of indicator $I_{i}$.

Henceforth, we refer to the three thresholds $\mathrm{p}_{\mathrm{i}}, \mathrm{q}_{\mathrm{i}}$ and $\mathrm{v}_{\mathrm{i}}$ collectively as thresholds of difference. A ranking process, based on the ELECTRE III outranking method (Roy, 1978) is conducted in three stages :

In Stage 1, concordance and discordance matrices, as defined below, are built. Concordance $\mathrm{c}_{\mathrm{i}}(\mathrm{a}, \mathrm{b})$ for each indicator $I_{i}$ is a measure of the truth of the statement that "a is at least as vulnerable as b according to indicator $\mathrm{I}_{\mathrm{i}}$ ”. This is based on rules i), ii) and iii), above. Discordance $d_{i}(a, b)$ for each indicator $I_{i}$ reflects the strength of evidence against the truth of the statement that “a is at least as vulnerable as $b$ according to indicator $\mathrm{I}_{\mathrm{i}}$ ”. Discordance is determined by $\mathrm{v}_{\mathrm{i}}$ which is called dominance threshold for indicator $\mathrm{I}_{\mathrm{i}}$ and reflects a difference between indicator values above which b becomes more vulnerable than a, regardless of the performances of a and $b$ on other indicators. This is based on rule iv), above. Hence, n concordance matrices and n discordance matrices are built, i.e. two matrices for each indicator. Each of these matrices have mxm dimension. Figure 2 graphically shows the variability of $\mathrm{c}_{\mathrm{i}}(\mathrm{a}, \mathrm{b})$ and $\mathrm{d}_{\mathrm{i}}(\mathrm{a}, \mathrm{b})$.

In Stage 2, an "outranking” matrix (mxm) is built as follows. The statement, “a is at least as vulnerable as b” is considered true provided:

i. a "majority” of indicators supports it (concordance principle); and

ii. no single indicator vetoes it (discordance principle). 
The concordance principle can be measured through the concordance index c(a,b) by the following equation:

$c(a, b)=\frac{1}{\sum_{i=1}^{m} w_{i}} \sum_{i=1}^{m} w_{i} c_{i}(a, b)$

where $\mathrm{W}_{\mathrm{i}}$ is a vote for indicator $\mathrm{I}_{\mathrm{i}}$, applied to the pair-wise comparisons (rather than a weight in a global utility function).

An outranking matrix combines the concordance and discordance principles in order to quantify the degree to which the statement "a is at least as vulnerable as b" is true (on a scale from 0 to 1 ). It is expressed by the following equation:

$S(a, b)=\left\{\begin{array}{lr}c(a, b) & \text { if } d_{i}(a, b) \leq c(a, b) \forall i=1, m \\ c(a, b) \prod_{i \in I_{v}(a, b)} \frac{\left[1-d_{i}(a, b)\right]}{[1-c(a, b)]} & \text { otherwise } \\ \text { where } I_{v}(a, b) \text { is the set of indicators for which } d_{i}(a, b)>c(a, b)\end{array}\right.$

In stage 3, called distillation and ranking stage, the outranking matrix is systematically analysed to generate rankings of the m SESs, according to the principle that the most vulnerable SES is the one that outranks the largest number of SESs and is outranked by least.

The determination of thresholds $\mathrm{q}_{\mathrm{i}}, \mathrm{p}_{\mathrm{i}}$ and $\mathrm{v}_{\mathrm{i}}$, as well as the votes $\mathrm{w}_{\mathrm{i}}$ is therefore an important part of problem definition, which in terms of vulnerability, can be defined and determined by the following questions (El-Zein and Tonmoy, 2015):

1. "All other indicators being equal, what is the difference in values of indicator $\mathrm{I}_{\mathrm{i}}$ for two SESs below which the vulnerabilities of the two systems are the same?" (indifference threshold qi).

2. "All other indicators being equal, what is the difference in values of indicator $I_{i}$ for two SESs above which one system is strictly more vulnerable than the other?” (relative vulnerability threshold $\mathrm{p}_{\mathrm{i}}$ ).

3. "What is the difference in values of indicator $\mathrm{I}_{\mathrm{i}}$ for two SESs above which one system is strictly more vulnerable than the other AND no advantage by any other indicator, or combination of other indicators, can compensate for it?” (dominance threshold $\mathrm{v}_{\mathrm{i}}$ ).

4. "In determining whether a 'majority' of indicators support the statement that one SES is at least as vulnerable as another, what is the strength of the 'vote' by indicator $\mathrm{I}_{\mathrm{i}}$ relative to a reference indicator?” (vote $\mathrm{w}_{\mathrm{i}}$ ).

Note that the preposition "All other indicators being equal" is used only for the purpose of eliciting thresholds for individual indicators from stakeholders and that, in generating rankings the outranking analysis considers ALL indicators together.

The thresholds of difference can be derived through two types of reasoning, depending on the indicator in question: 
1. from estimates by experts;

2. as a "value judgement” by stakeholders.

The first type of reasoning can be illustrated by referring to the case of the $\$$ value of damage to an infrastructure component (e.g., water main) as an indicator representing exposure (SEVA-INFRA, I1 to I7). To determine the indifference threshold for this indicator, SCC engineers and financial managers were asked to provide a \$ value below which the damage, or difference in damage to a component between two SESs, is considered insignificant. This could be based on the modus operandi of the SCC and would mirror thought processes of these experts. An example of the second type of reasoning is the degree of importance of, and ability to do without, a particular service provided by an infrastructure system to the community, as an indicator representing adaptive capacity (I13-I19). If the stakeholders chose to single out one particular service as being indispensable, a dominance threshold can be introduced to reflect this judgment.

It is important to keep in mind that the distinction between these two types of reasoning is not always clear cut: “estimates” by experts carry "value judgment” and "opinions” of stakeholders can also be partly based on "expertise”. Therefore, while the distinction was useful in discussions with stakeholders to elicit thresholds of difference, it did not have any further effects on the SEVA outranking analyses.

Clearly, the success of the assessment exercise depends on the ability to communicate to Council stakeholders the definitions of thresholds and weights, given above, and to elicit their values for each indicator. As will be shown below, the set of thresholds and weights constitute a structure expressing the stakeholders knowledge and value judgments about the vulnerability of the SESs in question and how to compare them.

\subsubsection{Drawbacks of the Outranking Approach}

An obvious drawback of outranking aggregation is its complexity, relative to arithmetic aggregation approaches, especially when it comes to communicating the assessment exercise to stakeholders. Two other drawbacks, called intransitivity and rank reversal, are counter-intuitive outcomes which are sometimes generated by outranking analyses. Intransitivity is the change in rankings when a set of alternatives is decomposed into smaller sets under otherwise identical conditions. Rank reversal occurs when the replacement of a low-ranked SES with a worse one leads to a change of rankings amongst the more highly-ranked SESs. Intransitivity and rank reversal are the effects of binary relations of indifference and uncertainty in preference structures and have been extensively discussed in the outranking literature (see for example Figueira et al, 2010; Roy and Martel, 2006). Fortunately, it is easy to test results in order to establish whether either of these two features is occurring, especially when the assessment is for a relatively small number of SESs, as is the case here.

\section{INFORMATION FLOW AND DATA COLLECTION PROCESS}

A flow diagram, shown in Figure 3, illustrates the flow of information in this study. The process started with a preliminary discussion with experts from the environmental planning department of the SCC regarding the goals, objectives and methods of the study. The following stakeholders from the SCC were consulted: 
- Shoalwater (responsible for developing and managing water supply and sewerage infrastructure of Shoalhaven);

- The transportation division (responsible for managing roads);

- Environmental and coastal planning division (responsible for long term coastal planning);

- Tourism department;

- Asset management department.

Ten SCC staff in total participated in the exercise, including 2 water supply engineers, 2 transportation engineers, 3 coastal planners, 2 asset management specialists and one tourism specialist. Following a preliminary discussion with the "Manager, natural resource and floodplain" of SCC, and a review of Shoalhaven hazard studies and other relevant literature, a conceptual model of the vulnerability of Shoalhaven beaches was developed, as described earlier. Next, in a first phase of consultation, a list of vulnerability indicators was proposed to the stakeholders of the SCC, who then selected those that are deemed most relevant to the context of Shoalhaven.

The aim of the second phase of consultation was to populate the vulnerability matrix by finding the scores for each beach, against each indicator. This was done in collaboration with the engineers and experts from respective departments of the SCC. The second phase of consultation also identified the interdependencies and dependencies of the Shoalhaven infrastructure systems which were needed for developing the infrastructure interdependency model discussed earlier.

The third phase of consultation was conducted through a one-day workshop to which the stakeholders listed above were invited. The aim of the workshop was to generate the thresholds of difference and votes, defined earlier, and which are required for aggregating indicators using outranking procedures. This was done in 4 steps and followed a 'Delphi' approach of stakeholder engagement (Lim et al., 2005). First, the goal of the study and the vulnerability framework were presented by the authors to the congregants, including the four questions listed in the previous section by way of defining the thresholds of difference and votes. In addition, examples illustrating the meaning of thresholds and votes were presented to the congregants based on simple analogies. Second, after a plenary discussion, including questions and answers, the stakeholders were asked to consider each indicator separately and to write on a piece of paper their estimate of the thresholds of difference and votes anonymously, unseen by others. A small number of generic limit cases were made available to participants as possible choices and displayed on a white board to simplify the task; these are:

1. "no indifference and no veto" represented by $q=0, p=0, v=\infty$ (no specific values required as input for thresholds). This was used when a) any difference, no matter how small, between the indicators of two SESs makes one more vulnerable than the other and b) vulnerability of an SES based on one indicator can be compensated for by its performance based on other indicators.

2. "from indifference to veto" represented by $\mathrm{q}=\mathrm{p}=\mathrm{v}$ (only one value required as input for thresholds). This was used when a) any difference, beyond a fixed value, between the indicators of two SESs makes one more vulnerable than the other and b) vulnerability of an SES based on one indicator cannot be compensated for by its performance based on other indicators. 
3. "no weak preference and no veto" represented by $\mathrm{q}=\mathrm{p}$ and $\mathrm{v}=\infty$ (only one value required as input for thresholds). This was used when a) any difference, beyond a fixed value, between the indicators of two SESs makes one more vulnerable than the other and b) vulnerability of an SES based on one indicator can be compensated for by its performance based on other indicators.

Third, assessments were collected by the facilitator, entered into a spreadsheet, differences between responses of different participants identified, and results presented to the congregants and extensively discussed. This step helped clarify the concepts further and generate a more commonly shared understanding of each variable. Note, that while presenting the results, anonymity of the respondents were maintained. Finally, based on the discussions, the congregants were given the opportunity to modify their original estimates and supply a new one, once again privately. An average of these final estimates was then taken as the adopted thresholds of difference. These are shown in Tables A28-A33 in the supplementary materials.

A final meeting was held about a year later, after our analyses had been completed, in order to communicate our findings, and discuss them with the SCC. Generated rankings were presented and discussed. Present at this meeting were, in addition to a number of stakeholders involved earlier in the project, a number of senior management personnel, who had not been hitherto involved in the project.

During the $2^{\text {nd }}$ and $3^{\text {rd }}$ consultation stages, a number of questions arose which can be seen as matters of community preferences and value judgment for the SCC stakeholders and the Shoalhaven community at large. For example, answers to some questions about scores, thresholds of difference or votes, clearly depended on whether expert opinion should be preferred over collective stakeholder opinion, should they diverge. Another example, is whether protection of private properties should be given lower priority than public assets. While in many domains, such as mitigation of erosional hazards, public amenity takes precedence over private interests in New South Wales statutes, there is a wide margin of interpretation (Thom, 2012). Hence, five questions such as the above two, deemed likely to have strong influence on the outcome of our analyses were identified. Based on this, a number of scenarios were built, reflecting different preferences and/or values guiding decision-making, in order to allow us to explore their effects on rankings. These scenarios are described in Table 4 (a further explanation of these scenarios is provided in the supplementary material Table A34).

A SEVA-Outranking tool developed earlier by the authors (El-Zein and Tonmoy, 2015) was used for the analyses. The tool had been programmed in MATLAB and validated against an independent outranking software.

\section{RESULTS OF ANALYSES}

\subsection{Vulnerability Rankings}

\subsubsection{Introduction}

Three sets of analyses were conducted: 
1. Base-case scenario using both SEVA and conventional additive aggregation in order to evaluate the extent to which an outranking approach yields different results;

2. Five alternative scenarios described earlier

3. Robustness analyses applied to the base case in order to a) assess the sensitivity of rankings to changes in votes and thresholds of difference and b) test for intransitivity and rank reversal, discussed earlier.

In each case, analyses were conducted separately for each vulnerability dimension (exposure, sensitivity, adaptive capacity), as well as in a set combining indicators from all dimensions. We refer to an aggregation using only exposure indicators as an "exposure analysis”. A similar convention is used for sensitivity-only indicators (“sensitivity analysis”) and adaptive-capacity-only indicators (“adaptive capacity analysis”). The fourth type of analyses using indicators under all three dimensions together is referred to as “combined analysis”.

In presenting rankings, the following conventions are adopted:

a) for exposure and sensitivity rankings, 1 is the most exposed/sensitive beach, while 8 is the least exposed/sensitive one.

b) for adaptive capacity ranking, 1 is the beach with least adaptive capacity, while 8 has the highest.

c) for combined rankings, 1 is the most vulnerable of the beaches, while 8 is the least vulnerable.

In other words, 1 always reflects highest vulnerability and 8 lowest. For each scenario, the Spearman correlation factors (SCF) were also calculated. This is a measure of the differences in ranking from the base case $(0 \leq \mathrm{SCF} \leq 1$; when SCF=1, the rankings generated by the base case and modified case are identical).

\subsubsection{Base-case scenario}

Mollymook has the highest possible damage cost of public infrastructure and was ranked as the most exposed beach, when aggregation is conducted by outranking (Table 4 first 5 columns). The SD model for Mollymook predicts that a maximum of 5,855 households would be affected by disruption of service during and after the storm event, making it the most "sensitive” of all eight beaches. In terms of adaptive capacity, Mollymook has the least capacity to adapt in the sense that the SCC has little or no capacity to provide an alternative option if there is interruption in the operation of sewerage pumping stations present at the beach. In addition, a collector road (Mitchell parade) at Mollymook has a high traffic volume (Annual Average Daily Traffic) and is at risk of inundation during the storm event. This would cause a loss of direct access to 22 properties and the diversion of large volume of traffic to an alternative route.

One notable feature of the rankings of the base case is Callala's change in ranking under different dimensions. The exposure rankings are dictated by the risk to public amenities (I7) which contributes to the top rank of Mollymook and places Warrain and Shoalhaven Heads $2^{\text {nd }}$, and Callala $4^{\text {th }}$. On the other hand, the Callala beach is ranked $2^{\text {nd }}$ alongside Warrain and Collingwood when the combined analysis is run. This is due to the fact that the difference in values of $\mathrm{I7}$ for, on the one hand, Warrain and Callala and, on the other hand, Collingwood, exceeds the dominance threshold for this indicator $(\$ 310,000)$. This means that the exposure of the former two beaches is so high, in comparison with the latter, that no performance on other indicators can compensate for it. Shoalhaven 
Heads too, judging by I7, has high vulnerability. However, its combined ranking is low because of its performance on other indicators.

When a simple additive weight approach (SAW) is used for aggregation, with votes acting as weights, different rankings are obtained (as reflected by the Spearman correlation factors) although Mollymook and Collingwood generally still dominate the top ranks. For example, Shoalhaven Heads and Warrain, which were ranked jointly $2^{\text {nd }}$ most exposed beaches by the outranking method as a result of the veto threshold of I7, were ranked $3^{\text {rd }}$ and $4^{\text {th }}$ respectively by SAW. This is because SAW is premised on full compensation which reduces the impact of the high value of I7 for the two beaches in question.

\subsubsection{Five Scenarios}

\section{Scenario 1: all stakeholders}

Adopting average threshold obtained from all stakeholders, rather than those from relevant experts, did not have a significant effect on the results. Average thresholds obtained from all stakeholders tended to be smaller (i.e., more stringent) than those given by the relevant experts (see table A30 in supplementary material). Therefore, dominance was more likely to occur. This was especially true for the beaches in the middle to bottom part of the ranking (e.g., Culburra, Currarong and Callala). Most notably, Callala was ranked $2^{\text {nd }}$ most vulnerable in the combined analysis in the base case but dropped to $4^{\text {th }}$ position when average preferences of all stakeholders were used in scenario 1.

\section{Scenario 2: service preference}

Warrain and Shoalhaven Heads were ranked as the $2^{\text {nd }}$ most exposed beaches in the base case, largely because of the high financial value of their respective surf clubs. However, in scenario 2, where the service value of the infrastructure systems was given higher prominence relative to the replacement cost (in effect giving a certain degree of priority to water, sewerage and road infrastructures over other public amenities), Collingwood rose from $4^{\text {th }}$ to $2^{\text {nd }}$ place, essentially swapping position with Warrain and Shoalhaven Heads. This is due to the presence in Collingwood of infrastructure assets, whose replacement value is lower than the surf clubs but provides critical services. A similar effect was at play in the sensitivity analyses where Culburra rose in ranking from $6^{\text {th }}$ position in the base case to $3^{\text {rd }}$ position under scenario 2 .

\section{Scenario 3: sewerage preference}

When higher importance was given to the services provided by sewerage systems, compared to other infrastructure services, Collingwood's exposure rose in ranking from $4^{\text {th }}$ to $2^{\text {nd }}$ position. Once again, rankings of the exposure of Warrain and Shoalhaven Heads dropped because the impact of the risk to the surf clubs was less important under scenario 3. In addition, indicator I7, reflecting the value of public amenities such as Golf and surf clubs, was no longer allowed dominance (i.e., high vulnerability on account of I7 can be compensated for by low vulnerability on account of other indicators, no matter how large I7 may be). This has led to higher rank of the exposure of Callala and Currarong, and lower rank for Warrain and Shoalhaven Heads, relative to the base case scenario. Clearly, this echoes scenario 2, and the two scenarios can be seen as reflecting a single, underlying value in which 
priority is given to vital infrastructure, relative to more leisure-oriented ones, regardless of the financial worth of assets.

\section{Scenario 4: private properties a}

Under scenario 4, the effect on beach residents is considered, rather than the impacts of disruption to infrastructure services. Collingwood, with the highest number of at-risk private properties and highest damage cost was ranked as the most sensitive and most exposed of the Shoalhaven beaches. However, the adaptive capacity of this beach was ranked relatively high, as a result of higher median household income and lower percentage of single parent households. These socio-economic indicators are likely to be correlated with the median property value of Collingwood, which partly explains the high asset values of exposed properties. However, another reason for the high vulnerability of Collingwood is the relatively large number of houses falling within the hazard line, which is unlikely to be related to the median property price. Mollymook, which was ranked as the most vulnerable beach in the base case (SEVA-INFRA), was ranked $2^{\text {nd }}$ after Collingwood under this scenario. Although Mollymook has a smaller number of at-risk private residential properties than Callala, the at-risk golf course of Mollymook - a commercial property - increased this beach's exposure and sensitivity.

\section{Scenario 5: private properties $b$}

Mollymook beach was the only beach with a commercial property (golf course) at risk and has led to its relatively high ranking under the previous scenario. A question therefore arises as to whether the two types of properties commercial and residential - should be given the same priorities. Under the previous scenario, impact on commercial properties was quantified through separate indicators, hence indirectly increasing their importance in the ranking algorithm. Under scenario 5, commercial properties are lumped with private ones. The effect of this change was to lower the exposure ranking of Mollymook from $2^{\text {nd }}$ to $4^{\text {th }}$. Otherwise, the rankings yielded by scenarios 4 and 5 are almost identical.

\subsubsection{Robustness Analyses}

Results of the two robustness tests (sensitivity and rank reversal) are shown in tables A35 to A37 of the supplementary material. Sensitivity of rankings to $\pm 5 \%$ changes in thresholds of differences (q, p and $v$ ) for each indicator relative to the base case, was established, one indicator at a time. The second test of robustness, the presence of rank reversal, was conducted by re-analyzing the combined rankings of the base case with one beach at a time modified by giving it the same scores as that of the least vulnerable beach (Collers) and observing whether unexpected changes in ranking occurs. Overall, both of these tests produced stable rankings with minor variations and no significant rank reversal occurring.

\section{DISCUSSION}

\subsection{Background}

Local councils around the world are developing policy to help coastal communities adapt to rising sea levels. The multi-scale nature of both vulnerability and adaptation to climate change adds a layer of complexity to policy making for two reasons (Lin et al., 2014). First, ecological processes generating coastal vulnerability to sea-level rise operate at global, regional and local scales (e.g., global climate change, regional coastal processes along 
Australian coastline, and local morphology and local sedimentary budgets of beaches and estuaries). An analogous statement can be made about the socio-economic dimension of vulnerability (sometimes called social vulnerability) whereby access to resources in the form of financial, cultural and social capitals is determined by such factors as, on the one hand, national insurance schemes and welfare protection nets and, on the other hand, the particular demographic characteristics and the strength of social networks in a given locality (Eakin et al., 2014).

Second, whereas local councils are often responsible for developing and implementing policy (as is the case in Australia), regulatory and legal requirements at regional or national levels can severely limit or expand the range of available policy options (Eisenack et al., 2014). Cultural values and preferences, as well as financial resources available to local councils can vary from one locality to another and can, alongside local politics, significantly affect what aspect of a community's life is seen as vulnerable and what kind of adaptation is deemed feasible and/or desirable.

In this study, we conducted an indicator-based vulnerability assessment exercise at a local scale, as analytical input to a local council's policy-making process. The assessment identified and incorporated a set of locality-specific preferences that are relevant to the exercise, and used a novel aggregation outranking approach which, unlike utilitarian approaches, reflects the non-compensatory nature of processes generating vulnerability. In what follows, we return to the research questions we set ourselves in the introduction and discuss two important aspects of our findings, namely the extent to which a local-scale assessment, such as the one conducted here, is useful for adaptation policy-making, and whether an outranking framework is viable as an aggregation approach in such a context.

\subsection{Benefits of Vulnerability Assessments at Local Scale}

A meta-analysis of the literature recently conducted by the authors found that most vulnerability assessments in the literature are performed at regional or national levels, and very few at a local or municipal scale (Tonmoy et al., 2014). Two questions are therefore especially pertinent to the assessment exercise reported here. How useful is a local, indicator-based vulnerability assessment? How does fit in with, or feed into, the development of adaptation policy and measures?

Three advantages of the assessment exercise became evident, during the process of conducting it, and in the final workshop where results were communicated to the SCC. First, compiling and aggregating place-specific data relating to both physical and socio-economic dimensions of vulnerability has allowed structured, datainformed discussions about vulnerability to be had, both amongst Council stakeholders and between the authors and Council stakeholders. This has led to significant changes of perception. For example, in the final workshop where results were presented to, and discussed by, SCC stakeholders, one participant stated that he had believed Shoalhaven Heads to be more vulnerable than Mollymook and Collingwood, because of the former's flooding history. The consideration of living communities and specific infrastructure systems present at the beaches, yielded a different assessment to the one that might have been obtained based on exposure and flooding histories alone, and therefore helped changed perceptions of local vulnerability. What is crucial here is the ability to structure vulnerability data in an easily communicable way, while incorporating place-specific information into 
the assessment exercise. For example, prior to the study, the Office of Environment and Heritage (OEH) in NSW had identified three beaches in Shoalhaven (Mollymook, Collingwood and Callala) as "authorized locations” under the Coastal Protection Act 1979, which allowed beach front private property owners to build coastal protection without any further approval if erosion level were to reach a certain threshold. This selection had been mainly guided by the proximity of the properties to an erosion-prone coast and had been questioned by residents of other exposed beaches whose properties did not benefit from the same status. Our vulnerability study triggered a discussion amongst Council stakeholders about the criteria used for the determination of “authorized locations” and helped the Council reinforcing the selection of the "authorized locations”.

Second, the process of developing the two models, including the component representing the inter-dependent infrastructure systems, has identified key local vulnerabilities, even prior to any aggregation of data. For example, in the case of Mollymook beach, the analyses revealed possible propagation to neighboring suburbs of a disruption to the two sewerage pumping stations. In addition, alongside the same beach, the analyses highlighted the extent of potential disruption to traffic on Mitchell parade, a major collector road connecting the southern and northern parts of Shoalhaven. During the workshops, Council officers from the water and transport section stated that modeling infrastructure-interdependency helped them see the bigger picture concerning disruption to an infrastructure node.

Third, another advantage of this type of place-specific data generated by the process of building the two models is that they point to possible adaptation options. Transferring the sewerage pumping stations to a less exposed location and building flood protections for parts of Mitchell road are two obvious options (though not the only ones and may or may not be the preferred ones from a cost-benefit perspective). The data can certainly enrich local discussions about adaptation by ensuring key issues are not left out (e.g., amongst the Mollymook community, with or without the involvement of the SCC).

The initial study conducted by Adamantidis et al. (2009) initially identified the eight beaches as especially exposed to the effect of sea level rise as these beaches mostly have erodible shoreline with low-lying highly developed areas with ongoing beach erosion and flooding issues. Given the high cost of detailed studies of adaptation options, including engineering protection options, the SCC needed to prioritise amongst these beaches. The ranking generated by the present study provided critical input into the prioritisation process, according to SCC officers, and Collingwood, Mollymook and Callala were subject to further adaptation studies. (See Tonmoy et al, 2015 for an example)

\subsection{Challenges and Limitations of Vulnerability Assessments}

A number of challenges and limitations emerged during the study, all of which reduced the ability of the local vulnerability assessment to feed into bigger questions of adaptation policy. At the time of the study, local councils in Australia, including the SCC, were responsible for the development of Coastal Zone Management Plans (CZMP) which guides land use zoning and the granting of individual development applications. In addition, they were required by law to ensure the safety of properties. Consequently, a critical and pressing question for local councils was, and remains, how to deal with development applications and requests for building protection in areas falling within the hazard lines of sea level rise. These decisions are place-specific 
but they also require guidelines from other tiers of government, at State and Federal levels, not least because of the legal implications of these decisions and the risk of litigation to which local councils may be exposed. In addition, the impact of individual protections on larger-scale processes of erosion is necessary for taking into account environmental impacts of such approvals. Local vulnerability assessments of the kind conducted here have limited capacity to provide useful input into these decisions.

The smallest unit of analysis in the present study was a whole beach (i.e., the community of users of infrastructure systems located at the beach, or the beach residents, depending on whether SEVA-INFRA or SEVA-HOUSE is used). This was dictated by the availability of socio-economic data and makes the spatial resolution of the study too coarse for decisions made at the level of households or groups of households. In theory, the scale of the assessment could be refined and vulnerability comparisons could be conducted down to household scale. However, in practice, acquiring data for such assessments would be very difficult, especially because of privacy protections associated with national surveys that constitute the most viable source of socioeconomic information. For example, Koks et al. (2015) emphasized the spatial variability of vulnerability to floods in the Netherlands, whereby risk to life and livelihoods is more heterogeneous than generally assumed. Here, vulnerability assessment would need be enriched with household surveys and/or fine-scale qualitative research (e.g.,(Cinner et al., 2012) ).

The place-specific nature of the models developed here constitute, as stated earlier, one of their strengths but can also be a limitation when it comes to replicating the models in other settings. Some indicators have emerged from the specific context of the eight beaches studied here and may not be relevant to other contexts, or may have a different meaning in a different context (Tavares et al., 2015). Hence replicating the exercise in other settings may be expensive since the models have to be rebuilt through the same consultative process conducted here. The nature of exercise may also change in the process since different Councils may have different policy priorities and may therefore set different objectives to the assessment. Our models were partly shaped by those questions (focus on infrastructure services, specific scenario related to sewerage systems). Tavares et al. (2015) wrote that a "balance between conceptual comprehensiveness and geographical detail is required to render vulnerability assessments effective tools in risk management”. Our study has shown that another kind of balance may also be critical, namely the one between generic, widely applicable, and available, indicators and those that are place-specific. The question here is whether the often-stated need for replicability of the models to other contexts must be sacrificed in order to increase their local relevance. On the positive side, even if that was the case, replicability of methodological approach should still be an aspiration.

\subsection{Outranking Method and Thresholds of Difference}

The outranking method used in this research offers a more sophisticated alternative to additive aggregation of indicators typically used in indicator-based assessments. This is because the method allows a fuzzy-logic characterisation of the relationship between vulnerability and its proxy indicators as well as non-compensation between different indicators. This structure of relationships is expressed through a set of thresholds of difference and votes. The indifference and preference thresholds are difference in values of a given indicator beyond which vulnerability becomes significant, while a veto threshold is a difference beyond which compensation by other indicators is no longer possible. Finally, votes express the relative importance of different indicators when judging 
the balance of evidence in ranking vulnerabilities. One of our goals was to test, for the first time, whether these thresholds and votes can be explained to, and elicited from, stakeholders. As described earlier, in a one-day workshop especially set up for this purpose, we followed a three-step approach in which we provided the background and rationale for the thresholds and votes as well as their definitions.

The exercise was successful overall in the sense that it was possible to elicit the values and significantly narrow the difference of opinion between participants, despite the relative complexity of the concepts. The main difficulty arose from the fact that the outranking algorithm, unlike additive aggregation, is too complex to be conveyed in a one-day workshop. Hence, while participants understood the definition of thresholds and votes, we did not try to provide them with an understanding of how their valuations would affect rankings of vulnerability except in a very general sense. Furthermore, the complexity of the ranking algorithm made it difficult to convey the crucial difference between votes in an outranking algorithm and conventional weights in an additive utility function. This finding was echoed by Kodikara et al. (2010) who studied threshold elicitation for an MCDA water management problem and found that some participants preferred to leave the choice of thresholds to relevant experts precisely because of this difficulty. Finally, while indifference and veto thresholds were intuitive and rather straightforward, the preference threshold was more difficult to convey. A question remains therefore as to whether the advantages of an outranking approach offset these disadvantages, especially when the pool of stakeholders is broadened to include a wider community with a large range of educational background. One possible solution to the problem of complexity is to use an alternative outranking procedure, namely the Dominance-Based Rough-Set Approach which is easier to understand and has simpler preference thresholds requirements (Cinelli et al., 2014). Another alternative is, rather than explaining how the adopted outranking method works, to provide the stakeholders with rankings generated by additive (easy to understand) and outranking methods, side by side. Then, the differences in rankings between the two approaches are associated to specific parameters that are intuitively easy to grasp (e.g., veto or indifference threshold associated with a particular criterion), without going into the technical details of how the given threshold contributed to the ranking. Concurrently, for the sake of transparency, carefully drafted educational material that explains how the outranking method works can be made available online to interested stakeholders. Either way, these alternatives need to be tested in a real assessment exercise to evaluate their effectiveness.

Although SEVA framework has been developed and tested for conducting climate change vulnerability assessment, its key architecture and threshold elicitation techniques can be applied in conducting vulnerability assessments in general (i.e. environmental vulnerability, social vulnerability etc.). However, vulnerability models need to be tailored for the specific system whose vulnerability is being assessed.

\section{ACKNOWLEDGEMENTS}

We acknowledge Isabelle Ghetti and Ray Massie from Shoalhaven City Council for their invaluable contribution in helping data collection and organizing council stakeholder meetings for this project.

\section{REFERENCES}

ABS, 2003. Census time series profiles, Cat. No. 2003.0, Canberra. 
ADAMANTIDIS, C., NIELSEN, A. \& GLATZ, M. 2009. Shoalhaven Coastal Hazard Study- Summary reportprepared by SMEC Australia for Shoalhaven City Council.

BIRKMANN, J. 2007. Risk and vulnerability indicators at different scales: applicability, usefulness and policy implications. Environmental Hazards, 7, 20-31.

BLAIKIE P, C. T., DAVIS I, WISNER B 1994. At risk: natural hazards, people's vulnerability, and disasters. , Ruoutledge.

BÖHRINGER, C. \& JOCHEM, P. E. P. 2007. Measuring the immeasurable - A survey of sustainability indices. Ecological Economics, 63, 1-8.

BROOKS, N. 2003. Vulnerability, Risk and Adaptation: A Conceptual Framework, Working Paper 38. Tyndall Centre for Climate Change Research, University of East Anglia, Norwich.

CINELLI, M., COLES, S. R. \& KIRWAN, K. 2014. Analysis of the potentials of multi criteria decision analysis methods to conduct sustainability assessment. Ecological Indicators, 46, 138-148.

CINNER, J. E., MCCLANAHAN, T. R., GRAHAM, N. A. J., DAW, T. M., MAINA, J., STEAD, S. M., WAMUKOTA, A., BROWN, K. \& BODIN, Ö. 2012. Vulnerability of coastal communities to key impacts of climate change on coral reef fisheries. Global Environmental Change, 22, 12-20.

CLARK, G., MOSER, S., RATICK, S., DOW, K., MEYER, W., EMANI, S., JIN, W., KASPERSON, J., KASPERSON, R. \& SCHWARZ, H. 1998. Assessing the Vulnerability of Coastal Communities to Extreme Storms: The Case of Revere, MA., USA. Mitigation and Adaptation Strategies for Global Change, 3, 59-82.

CUTTER, S. L. 1996. Vulnerability to environmental hazards. Progress in Human Geography 20, 529-539.

CUTTER, S. L., MITCHELL, J. T. \& SCOTT, M. S. 2000. Revealing the vulnerability of people and places: A case study of Georgetown County, South Carolina. Annals of the Association of American Geographers, 90, 713-737.

EAKIN, H. C., LEMOS, M. C. \& NELSON, D. R. 2014. Differentiating capacities as a means to sustainable climate change adaptation. Global Environmental Change, 27, 1-8.

EBERT, U. \& WELSCH, H. 2004. Meaningful environmental indices: A social choice approach. Journal of Environmental Economics and Management, 47, 270-283.

EISENACK, K., MOSER, S. C., HOFFMANN, E., KLEIN, R. J. T., OBERLACK, C., PECHAN, A., ROTTER, M. \& TERMEER, C. J. A. M. 2014. Explaining and overcoming barriers to climate change adaptation. Nature Clim. Change, 4, 867-872.

EL HANANDEH, A. \& EL-ZEIN, A. 2010. The development and application of multi-criteria decision-making tool with consideration of uncertainty: The selection of a management strategy for the bio-degradable fraction in the municipal solid waste. Bioresource Technology, 101, 555-561.

EL-ZEIN, A. \& TONMOY, F. N. 2015. Assessment of vulnerability to climate change using a multi-criteria outranking approach with application to heat stress in Sydney. Ecological Indicators, 48, 207-217.

EL-ZEIN, A. \& TONMOY, F. N. 2017. Nonlinearity, fuzziness and incommensurability in indicator-based assessments of vulnerability to climate change: A new mathematical framework. Ecological Indicators, 82, 82-93.

FIGUEIRA, J., SALVATORE, G. \& EHRGOTT, M. 2005. Multiple Criteria Decision Analysis: State of the Art Surveys, New York, Springer.

FÜSSEL, H.-M. 2007. Vulnerability: A generally applicable conceptual framework for climate change research. Global Environmental Change, 17, 155-167.

HASAN, S., TONMOY, F. N., FOLIENTE, G. \& EL-ZEIN, A. 2015. Modelling infrastructure interdependency at a local scale: value, methodologies and challenges. 21st International Congress on Modelling and Simulation (MODSIM2015), At Gold Coast, Australia

HEWITT, K. 1997. Regions of risk: A geographical introduction to disasters, Longman (Harlow).

HOKKANEN, J. \& SALMINEN, P. 1997. ELECTRE III and IV Decision Aids in an Environmental Problem. Journal of Multi-Criteria Decision Analysis, 6, 215-226.

HOUGH, R. L., TOWERS, W. \& AALDERS, I. 2010. The Risk of Peat Erosion from Climate Change: Land Management Combinations-An Assessment with Bayesian Belief Networks. Human and Ecological Risk Assessment: An International Journal, 16, 962-976.

KANGAS. A, J. K. A. J. P. 2001. Outranking methods as tools in strategic natural resources planning. Silva Fennica, 35, 215-227.

KELLY, P. M. \& ADGER, W. N. 2000. Theory and practice in assessing vulnerability to climate change andFacilitating adaptation. Climatic Change, 47, 325-352.

KIENBERGER, S., BLASCHKE, T. \& ZAIDI, R. Z. 2013. A framework for spatio-temporal scales and concepts from different disciplines: the 'vulnerability cube'. Natural Hazards, 68, 1343-1369.

KLEIN, R. J. T. 2009. Identifying Countries that are Particularly Vulnerable to the Adverse Effects of Climate Change: An Academic or a Political Challenge? CCLR The Carbon \&\#38; Climate Law Review, 3, 284-291. 
KOKS, E. E., JONGMAN, B., HUSBY, T. G. \& BOTZEN, W. J. W. 2015. Combining hazard, exposure and social vulnerability to provide lessons for flood risk management. Environmental Science \& Policy, 47, 42-52.

MCINNES, K. L., WHITE, C. J., HAIGH, I. D., HEMER, M. A., HOEKE, R. K., HOLBROOK, N. J., KIEM, A. S., OLIVER, E. C. J., RANASINGHE, R., WALSH, K. J. E., WESTRA, S. \& COX, R. 2016. Natural hazards in Australia: sea level and coastal extremes. Climatic Change, 139, 69-83.

MCLAUGHLIN, S. \& COOPER, J. A. G. 2010. A multi-scale coastal vulnerability index: A tool for coastal managers? Environmental Hazards-Human and Policy Dimensions, 9, 233-248.

NIELSEN, L. \& VARLEY, I. Shoalhaven Coastline Hazard Definition Study by SMEC Australia Pty Ltd.

NSW, D. O. E. C. C. A. W. 2009. NSW Sea Level Rise Policy Statement (accessed at http://www.planning.nsw.gov.au/LinkClick.aspx?fileticket=ukmXcVJesYA\%3D\&tabid=177 on the 23rd October 2012). Sydney.

O'BRIEN, K., ERIKSEN, S., NYGAARD, L. P. \& SCHJOLDEN, A. 2007. Why different interpretations of vulnerability matter in climate change discourses. Climate policy, 7, 73-88.

REFSGAARD, J. C., VAN DER SLUIJS, J. P., HØJBERG, A. L. \& VANROLLEGHEM, P. A. 2007. Uncertainty in the environmental modelling process - A framework and guidance. Environmental Modelling \& Software, 22, 1543-1556.

ROY, B. 1968. Classement et choix en présence de points de vue multiples (la méthode ELECTRE)'. RIRO, 8, 57-75.

ROY, B. 1978. ELECTRE III: Un algorithme de classement fondé sur une représentation floue des préférences en présence de critères multiples. Cahiers du Centre d'Etudes de Recherche Opérationnelle, 20, 3-24.

ROYAL HASKONING DHV 2016. Currarong coastal erosion June 2016 storm and response (available at http://doc.shoalhaven.nsw.gov.au/DisplayDoc.aspx?record=D16/330107)

SHAND, T., CARLEY, J., YOU, Z. \& COX, R. Long-term trends in NSW coastal wave climate and derivation of extreme design storms. NSW Coastal Conference, 2011a. 8-11.

SHAND, T. D., COX, R. J., MOLE, M. A., CARLEY, J. T. \& PEIRSON, W. L. Coastal storm data analysis: provision of extreme wave data for adaptation planning. Coasts and Ports 2011: Diverse and Developing: Proceedings of the 20th Australasian Coastal and Ocean Engineering Conference and the 13th Australasian Port and Harbour Conference, 2011b. Engineers Australia, 170.

SHOALHAVEN CITY COUNCIL 2017. Population and household forecasts for Shaolhaven 2011 to 2036 Available at (http://forecast.id.com.au/shoalhaven).

SHOALHAVEN WATER 2012. Shoalhaven Water Strategic Business Plan 2011-2012. Shoalhaven, NSW.

STERR, H., KLEIN, R. J. \& REESE, S. 2003. 12. Climate change and coastal zones: an overview of the stateof-the-art on regional and local vulnerability assessment. Climate change in the Mediterranean: Socioeconomic perspectives of impacts, vulnerability and adaptation, 245.

STRATEGIC PLANNING \& INFRASTRUCTURE GROUP 2012. Asset Management Plan: Transport Infrastructure (Sealed Roads). Nowra, NSW: Shoalhaven City Council.

TAVARES, A. O., DOS SANTOS, P. P., FREIRE, P., FORTUNATO, A. B., RILO, A. \& SÁ, L. 2015. Flooding hazard in the Tagus estuarine area: The challenge of scale in vulnerability assessments. Environmental Science \& Policy, 51, 238-255.

THOM, B. 2012. Climate change, coastal hazards and the public trust doctrine. Macquarie J. Int'l \& Comp. Envtl. L., 8, 21.

TOBIN, G. \& MONTZ, B. 1997. Natural hazards: explanation and integration, New York Guildford Press.

TONMOY, F. N. \& EL-ZEIN, A. Vulnerability of infrastructure to Sea Level Rise: A combined outranking and system-dynamics approach. European Safety and Reliability (ESREL-2013), 2013. CRC Press, pp 509. ISBN: 978-1-315-81559-6, 2407-2414.

TONMOY, F. N., ELLEIN, A. \& HINKEL, J. 2014. Assessment of vulnerability to climate change using indicators: a metaCanalysis of the literature. Wiley Interdisciplinary Reviews: Climate Change, 5, 775792.

TONMOY, F., BROWN, M., POLYDOROPOULOS, P. \& EL-ZEIN, A. 2015. A comparative analysis of engineering options for adaptation to sea-level rise: a case study for a vulnerable beach in Shoalhaven NSW, MODSIM 2015: 21st International Congress on Modelling and Simulation, Gold Coast, Australia

UNITED NATIONS, POPULATION DIVISION: 2012. World Urbanization Prospects, the 2011 Revision: Highlights. New York.

WALSH, K., BETTS, H., CHURCH, J., PITTOCK, A., MCINNES, K., JACKETT, D. \& MCDOUGALL, T. 2004. Using sea level rise projections for urban planning in Australia. Journal of Coastal Research, 586-598. 
WU, J., JONES, B., LI, H. \& LOUCKS, O. L. 2006. Scaling and uncertainty analysis in ecology. Methods and applications. Springer, Dordrecht, the Netherlands.

WU, S.-Y., YARNAL, B. \& FISHER, A. 2002. Vulnerability of coastal communities to sea-level rise: a case study of Cape May County, New Jersey, USA. Climate Research, 22, 255-270. 


\section{Tables}

Table 1: Key definitions for vulnerability models

\begin{tabular}{|c|c|c|}
\hline & Vulnerability Model 1: SEVA-HOUSE & Vulnerability Model 2: SEVA-INFRA \\
\hline $\begin{array}{l}\text { Whose vulnerability? } \\
\text { (SESs) }\end{array}$ & Eight beach communities in $\mathrm{SC}^{1}$ & $\begin{array}{c}\text { Users of infrastructure located at eight } \\
\text { beaches in } \mathrm{SC}^{2}\end{array}$ \\
\hline $\begin{array}{l}\text { Vulnerability of } \\
\text { which valued } \\
\text { attribute of the SESs? }\end{array}$ & Well-being of communities & $\begin{array}{c}\text { Well-being of users to the extent that it is } \\
\text { affected by the infrastructure services in } \\
\text { question }\end{array}$ \\
\hline $\begin{array}{l}\text { Vulnerability to what } \\
\operatorname{hazard}(\mathrm{s}) ?\end{array}$ & $\begin{array}{c}\text { Storm event of similar characteristics to } \\
\text { the one that occurred in } 1974 \text { but under } \\
0.4 \mathrm{~m} \text { sea-level rise scenario } \\
\end{array}$ & $\begin{array}{c}\text { Storm event similar to one that occurred in } \\
1974 \text { but under } 0.4 \mathrm{~m} \text { sea-level rise } \\
\text { scenario }\end{array}$ \\
\hline $\begin{array}{l}\text { Vulnerability at what } \\
\text { point in time? }\end{array}$ & At time of study (2013-2014) & At time of study (2013-2014) \\
\hline Assessment Goal & $\begin{array}{c}\text { Rank vulnerabilities of well-being of } 8 \\
\text { beach communities to a storm event of } \\
\text { similar characteristics to the one that } \\
\text { occurred in } 1974 \text { albeit under } 0.4 \mathrm{~m} \text { sea- } \\
\text { level rise scenario, should this event occur } \\
\text { today. }\end{array}$ & $\begin{array}{l}\text { Rank vulnerabilities of well-being of users } \\
\text { of infrastructure systems located at the } 8 \\
\text { beaches, to a storm event of similar } \\
\text { characteristics to the one that occurred in } \\
1974 \text { albeit under } 0.4 \mathrm{~m} \text { sea-level rise } \\
\text { scenario, should this event occur today. }\end{array}$ \\
\hline
\end{tabular}

${ }^{1}$ defined as the coastal State Suburb Level which was the lowest statistical unit for which socio-economic data was available;

${ }^{2}$ while some of these users may live at or near beaches, most do not. 
Table 2: Definitions of exposure, sensitivity and adaptive capacity for SEVA-INFRA and SEVA-HOUSE (SLRAP: Sea Level Rise and Associated Processes)

\begin{tabular}{|l|l|l|}
\hline Information Type & \multicolumn{1}{|c|}{ SEVA-INFRA } & \multicolumn{1}{|c|}{ SEVA-HOUSE } \\
\hline Exposure & $\begin{array}{l}\text { Extent to which public infrastructure systems are } \\
\text { exposed to SLRAP }\end{array}$ & $\begin{array}{l}\text { Extent to which houses and } \\
\text { households are exposed to SLRAP }\end{array}$ \\
\hline Sensitivity & $\begin{array}{l}\text { 1. Extent to which the well-being of the community } \\
\text { of users of the public infrastructure is likely to } \\
\text { suffer as a result of disruption to service; } \\
\text { 2. Extent to which, and speed with which, relevant } \\
\text { public authorities are able to repair damaged } \\
\text { infrastructure components and restore disrupted } \\
\text { services to users or offer substitute services }\end{array}$ & $\begin{array}{l}\text { Extent to which the well-being of } \\
\text { residents at the beach is likely to } \\
\text { suffer as a result of that exposure, } \\
\text { due partly, but not exclusively, to } \\
\text { infrastructure services }\end{array}$ \\
\hline Adaptive capacity & $\begin{array}{l}\text { Extent to which, and speed with which, users are } \\
\text { able to substitute, or do without, disrupted services, } \\
\text { without help from government institutions }\end{array}$ & $\begin{array}{l}\text { Extent to which households can } \\
\text { adapt to, and mitigate, the impact } \\
\text { on their well-being of exposure to } \\
\text { SLRAP. }\end{array}$ \\
\hline
\end{tabular}


Table 3: Vulnerability matrix of adaptive capacity (SEVA-HOUSE)

\begin{tabular}{|c|c|c|c|c|c|c|c|c|c|c|c|}
\hline & Code & Indicators & Unit & Mollymook & Collingwood & Callala & Currarong & Warrain & Culburra & $\begin{array}{c}\text { Shoalhaven } \\
\text { Heads }\end{array}$ & Collers \\
\hline \multirow{5}{*}{$\begin{array}{l}\text { Demo- } \\
\text { graphic } \\
\text { profile } \\
\text { of the } \\
\text { whole } \\
\text { beach* }\end{array}$} & $\mathrm{I} 25$ & $\begin{array}{l}\% \text { of population attending } \\
\text { secondary education }\end{array}$ & \multirow{4}{*}{$\%$} & 23 & 21 & 21 & 17 & 26 & 26 & 21 & 23 \\
\hline & I26 & \% of population under 19 & & 20 & 20 & 23 & 21 & 20 & 20 & 18 & 22 \\
\hline & $\mathrm{I} 27$ & $\%$ of population over 60 & & 37 & 37 & 39 & 36 & 38 & 38 & 41 & 36 \\
\hline & $\mathrm{I} 28$ & \% of single-parent household & & 16 & 13 & 18 & 9 & 18 & 18 & 14 & 14 \\
\hline & I29 & $\begin{array}{l}\text { median weekly household } \\
\text { income }\end{array}$ & AUD & 791 & 935 & 724 & 845 & 757 & 757 & 691 & 816 \\
\hline
\end{tabular}

*source of these data is the ABS demographic profile 2011. Demographic profile of Warrain is not available separately, rather in ABS data, it is included with Culburra. Therefore demographic profile of Culburra was adopted for Warrain. Again, demographic profile of Collers beach is not separately available. However, there is a data in ABS that includes most of the collrs beach. It is named as Mollymook with code SSC11570. This was used for Collers. 
Table 4: Vulnerability rankings of Shoalhaven beaches with scenario analysis. SCF: Spearman Correlation Coefficient (SCF for scenario 1 to 4 are calculated relative to the base case. SCF for scenario 5 are calculated relative to scenario 4); E: Exposure; S: Sensitivity; AC: Adaptive capacity; C: Combined ranking

\begin{tabular}{|c|c|c|c|c|c|c|c|c|c|c|c|c|c|c|c|c|c|c|c|c|c|c|c|c|c|c|c|c|}
\hline \multirow{2}{*}{$\begin{array}{l}\text { Scenario } \\
\text { Dimension }\end{array}$} & \multicolumn{4}{|c|}{ Base Case } & \multicolumn{4}{|c|}{$\begin{array}{l}\text { Base case- Simple } \\
\text { additive weight }\end{array}$} & \multicolumn{4}{|c|}{$\begin{array}{c}\text { Scenario-1 } \\
\text { Average stakeholder- } \\
\text { preference scenario }\end{array}$} & \multicolumn{4}{|c|}{$\begin{array}{c}\text { Scenario-2 } \\
\text { Service- } \\
\text { preference scenario } \\
\end{array}$} & \multicolumn{4}{|c|}{$\begin{array}{c}\text { Scenario-3 } \\
\text { Sewerage- } \\
\text { priority scenario }\end{array}$} & \multicolumn{4}{|c|}{$\begin{array}{c}\text { Scenario-4 } \\
\begin{array}{c}\text { Private property preference } \\
\text { scenario-a }\end{array} \\
\end{array}$} & \multicolumn{4}{|c|}{$\begin{array}{c}\text { Scenario-5 } \\
\text { Private property } \\
\text { preference scenario-b } \\
\end{array}$} \\
\hline & $\mathbf{E}$ & $\mathrm{S}$ & AC & C & $\mathbf{E}$ & $\mathrm{S}$ & AC & C & $\mathbf{E}$ & $\mathrm{s}$ & AC & C & $\mathbf{E}$ & $\mathrm{S}$ & AC & C & $\mathbf{E}$ & $\mathrm{s}$ & AC & C & $\mathbf{E}$ & $\mathrm{S}$ & AC & C & $\mathbf{E}$ & $\mathrm{S}$ & AC & C \\
\hline SCF & 1 & 1 & 1 & 1 & 0.85 & 0.80 & 0.87 & 0.59 & 0.99 & 0.94 & 1.00 & 0.94 & 0.69 & 0.89 & 1.00 & 0.81 & 0.69 & 0.89 & 0.98 & 0.64 & 0.01 & 0.51 & -0.13 & 0.82 & 0.92 & 1 & 1 & 1 \\
\hline Mollymook & 1 & 1 & 1 & 1 & 1 & 1 & 1 & 1 & 1 & 1 & 1 & 1 & 1 & 1 & 1 & 1 & 1 & 1 & 1 & 1 & 2 & 2 & 3 & 2 & 4 & 2 & 3 & 2 \\
\hline Collingwood & 4 & 2 & 2 & 2 & 2 & 2 & 2 & 2 & 4 & 2 & 2 & 3 & 2 & 2 & 2 & 2 & 2 & 2 & 2 & 2 & 1 & 1 & 8 & 1 & 1 & 1 & 8 & 1 \\
\hline Callala & 4 & 5 & 8 & 2 & 5 & 7 & 7 & 7 & 5 & 6 & 8 & 4 & 3 & 6 & 8 & 4 & 3 & 6 & 8 & 7 & 4 & 4 & 2 & 3 & 3 & 4 & 2 & 3 \\
\hline Currarong & 6 & 7 & 6 & 7 & 6 & 4 & 6 & 6 & 6 & 6 & 6 & 7 & 4 & 7 & 6 & 7 & 4 & 7 & 7 & 6 & 5 & 6 & 7 & 7 & 5 & 6 & 7 & 7 \\
\hline Warrain & 2 & 3 & 3 & 2 & 4 & 3 & 5 & 4 & 2 & 3 & 3 & 2 & 4 & 3 & 3 & 5 & 4 & 3 & 3 & 4 & 6 & 5 & 3 & 5 & 5 & 5 & 3 & 5 \\
\hline Culburra & 6 & 6 & 4 & 6 & 7 & 6 & 3 & 5 & 6 & 5 & 4 & 6 & 7 & 3 & 4 & 3 & 7 & 3 & 3 & 3 & 2 & 2 & 3 & 3 & 2 & 2 & 3 & 3 \\
\hline $\begin{array}{l}\text { Shoalhaven } \\
\text { Heads }\end{array}$ & 2 & 3 & 5 & 5 & 3 & 5 & 4 & 3 & 2 & 3 & 5 & 5 & 4 & 3 & 5 & 5 & 4 & 3 & 5 & 5 & 7 & 7 & 1 & 6 & 7 & 7 & 1 & 6 \\
\hline Collers & 6 & 8 & 6 & 8 & 8 & 8 & 8 & 8 & 6 & 6 & 6 & 8 & 7 & 8 & 6 & 8 & 7 & 8 & 6 & 8 & 7 & 7 & 6 & 7 & 7 & 7 & 6 & 7 \\
\hline
\end{tabular}




\section{Figures}
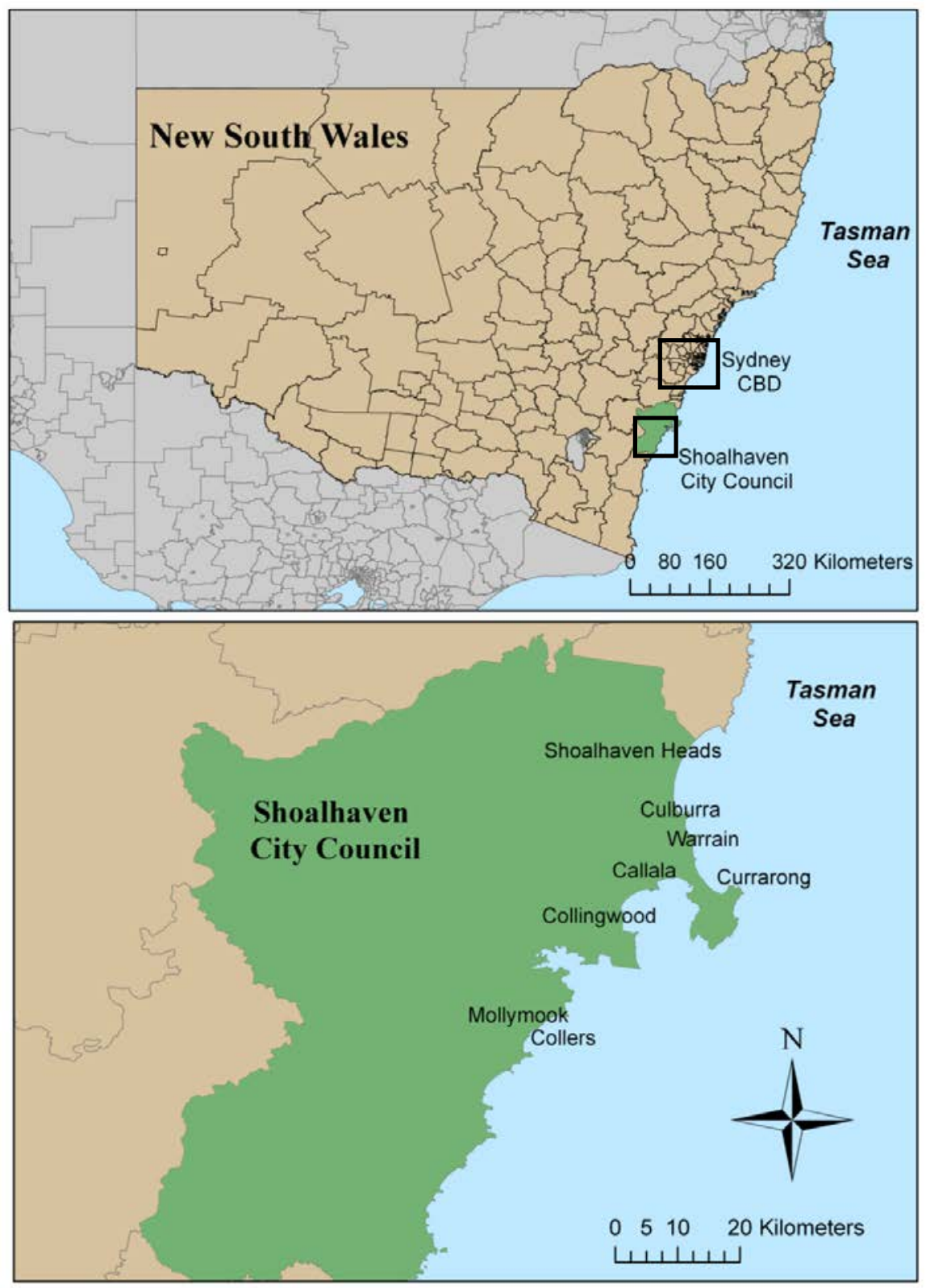

Figure 1. Study Area 


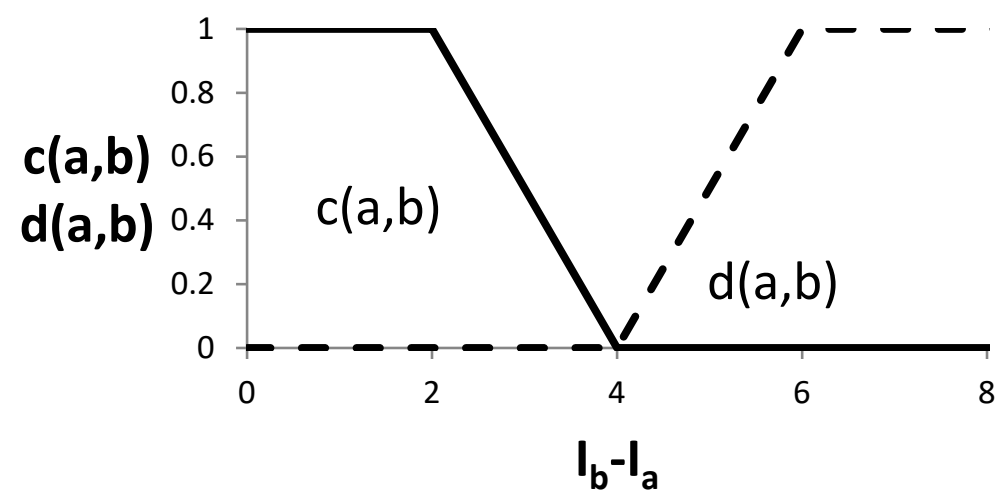

Figure 2. Vulnerability represented by a fuzzy-set relationship : concordance and discordance for $(q=2, p=4, v=6)$ 


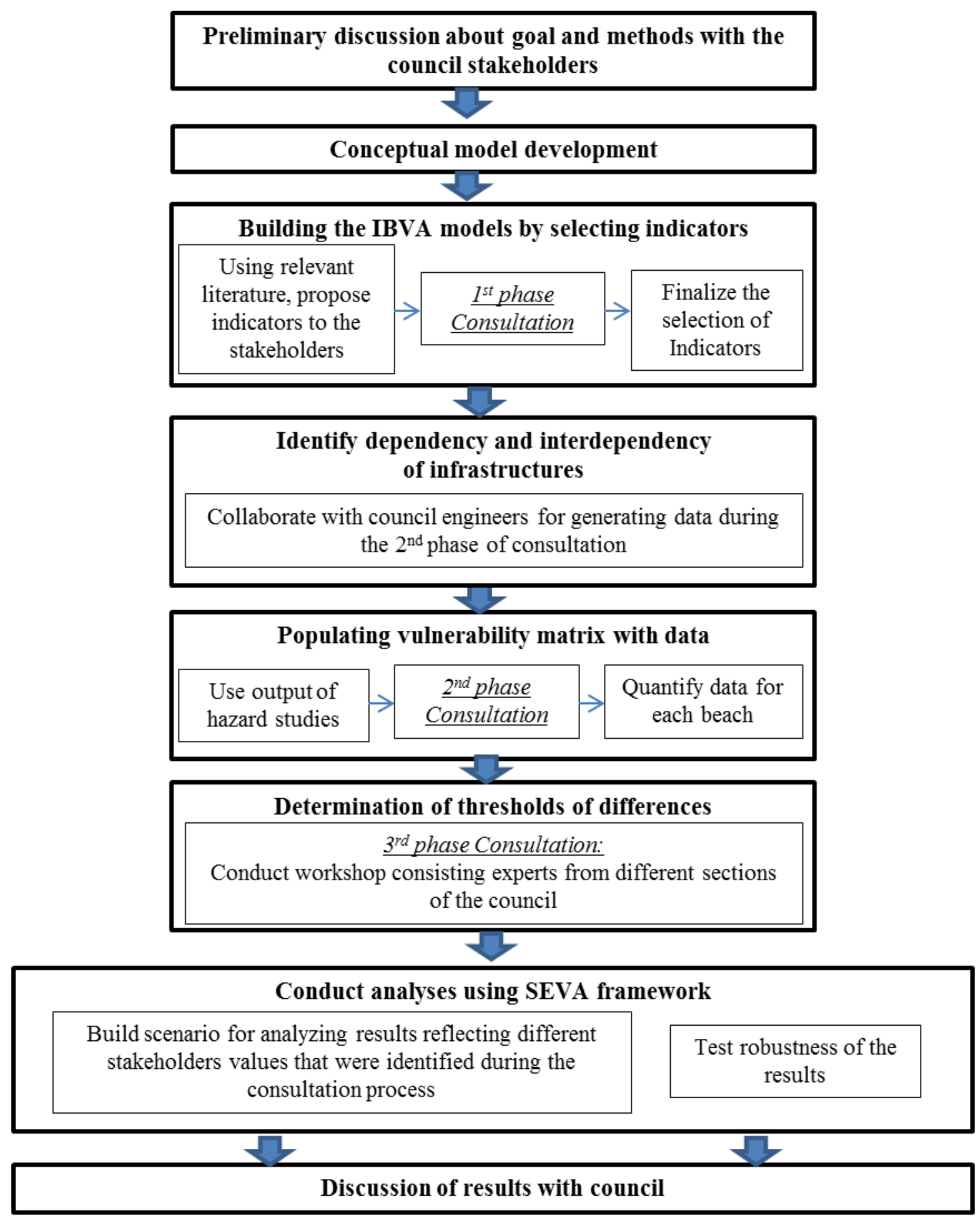

Figure 3. Process flow diagram of the study 